\title{
A system biology approach highlights a hormonal enhancer effect on regulation of genes in a nitrate responsive "biomodule" Damion Nero $^{\dagger 1}$, Gabriel Krouk ${ }^{\dagger 1}$, Daniel Tranchina ${ }^{1,2}$ and Gloria M Coruzzi*1
}

\author{
Address: ${ }^{1}$ Center for Genomics and Systems Biology, Department of Biology, New York University, 100 Washington Square East, 1009 Main \\ Building, New York, 10003, USA and 2Courant Institute of Mathematical Sciences, New York, 251 Mercer St, New York, NY, 10012, USA \\ Email: Damion Nero - den208@nyu.edu; Gabriel Krouk - gk40@nyu.edu; Daniel Tranchina - tranchin@courant.nyu.edu; \\ Gloria M Coruzzi* - gloria.coruzzi@nyu.edu \\ * Corresponding author †Equal contributors
}

Published: 6 June 2009

BMC Systems Biology 2009, 3:59 doi:10.1186/1752-0509-3-59
Received: 26 March 2009

Accepted: 6 June 2009

This article is available from: http://www.biomedcentral.com/I752-0509/3/59

(c) 2009 Nero et al; licensee BioMed Central Ltd.

This is an Open Access article distributed under the terms of the Creative Commons Attribution License (http://creativecommons.org/licenses/by/2.0), which permits unrestricted use, distribution, and reproduction in any medium, provided the original work is properly cited.

\begin{abstract}
Background: Nitrate-induced reprogramming of the transcriptome has recently been shown to be highly context dependent. Herein, a systems biology approach was developed to identify the components and role of cross-talk between nitrate and hormone signals, likely to be involved in the conditional response of $\mathrm{NO}_{3}{ }^{-}$signaling.

Results: Biclustering was used to identify a set of genes that are $\mathrm{N}$-responsive across a range of Nitrogen $(\mathrm{N})$-treatment backgrounds (i.e. nitrogen treatments under different growth conditions) using a meta-dataset of 76 Affymetrix ATHI chips from 5 different laboratories. Twenty-one biclusters were found to be $\mathrm{N}$-responsive across subsets of this meta-dataset. $\mathrm{N}$-bicluster 9 (I26 genes) was selected for further analysis, as it was shown to be reproducibly responsive to $\mathrm{NO}_{3}{ }^{-}$as a signal, across a wide-variety of background conditions and datasets. $\mathrm{N}$-bicluster 9 genes were then used as "seed" to identify putative cross-talk mechanisms between nitrate and hormone signaling. For this, the 126 nitrate-regulated genes in $\mathrm{N}$-bicluster 9 were biclustered over a meta-dataset of 278 ATHI chips spanning a variety of hormone treatments. This analysis divided the bicluster 9 genes into two classes: i) genes controlled by $\mathrm{NO}_{3}{ }^{-}$only vs. ii) genes controlled by both $\mathrm{NO}_{3}{ }^{-}$and hormones. The genes in the latter group showed a $\mathrm{NO}_{3}{ }^{-}$response that is significantly enhanced, compared to the former. In silico analysis identified two Cis-Regulatory Elements candidates (CRE) (E2F, HSE) potentially involved the interplay between $\mathrm{NO}_{3}{ }^{-}$and hormonal signals.
\end{abstract}

Conclusion: This systems analysis enabled us to derive a hypothesis in which hormone signals are proposed to enhance the nitrate response, providing a potential mechanistic explanation for the link between nitrate signaling and the control of plant development.

\section{Background}

Higher plants acquire nitrogen mainly as $\mathrm{NO}_{3}{ }^{-}$. The soil concentration of this mineral ion can fluctuate dramatically in the rhizosphere, often resulting in limited growth and yield [1]. Thus, nitrate signaling constitutes a key point of plant adaptation to environment. This is why nitrate signaling has so far been intensively studied by transcriptomic assays, involving more than 75 ATH1 
chips in various background conditions and treatments. Taken together these transcriptomic data showed that $\mathrm{NO}_{3}{ }^{-}$-responses are very context dependent $[2,3]$, suggesting that evolution probably built very adaptable and robust networks involved in the integration of $\mathrm{NO}_{3}{ }^{-}$with other signals including light, sugar, and hormones. For instance, as sessile organisms, plants have developed a strong capacity to modulate growth according to nutrient availability. On a molecular scale, this coordination between nutrition and growth can be mediated by the cocontrol of metabolism and hormonal signaling. For instance, a recent work reports that molecular reprogramming induced by nutritional starvation treatments significantly involve hormone regulated genes [4]. Moreover, it has also been shown that such cross-controls exist between $\mathrm{NO}_{3}{ }^{-}$and: cytokinin (for review see [5]), auxin $[2,6,7]$, and ABA [8]. To date, molecular players underlying those events are still under investigation. One striking example of such coordination at a molecular level is presented by the role of the iso-pentenyl-transferase 3 (IPT3) involved in the critical step of cytokinin biosynthesis. Transcription of the $\mathrm{NO}_{3}$ - induced gene IPT3 has been shown to be involved in the production of $\mathrm{NO}_{3}$ - induced cytokinins, hypothesized to coordinate shoot growth in response to $\mathrm{NO}_{3}{ }^{-}$provision [9-14].

Root architecture is also under the coordinated control of nutrient availability and hormone signaling [15]. For instance, $\mathrm{NO}_{3}{ }^{-}$controls root branching under various pathways (for review see $[16,17]$ ). Hormones have been shown to play important roles in the adaptation of root development to $\mathrm{NO}_{3}^{-}$availability. Indeed, $\mathrm{NO}_{3}$ - triggers root colonization in $\mathrm{NO}_{3}{ }^{-}$rich patch of the soil. Zhang et al [18] have shown that this adaptation could involve AXR4, a gene initially demonstrated to be involved in auxin signaling. Later, AXR4 was shown to be involved in targeting the auxin influx transporter AUX1 to the plasma membrane [19]. Thus AXR4 may provide a molecular link between the $\mathrm{NO}_{3}{ }^{-}$signal and auxin signaling through regulating auxin transport. Furthermore, the dual affinity (high and low affinity $\mathrm{NO}_{3}^{-}$uptake) $\mathrm{NO}_{3}^{-}$transporter NRT1.1/CHL1, hypothesized to be a part of the $\mathrm{NO}_{3}^{-}$sensing system [20-23], was previously shown to be regulated by auxin [7]. This evidence uncovers one facet of how the $\mathrm{NO}_{3}$ - sensing system is likely tuned by a hormonal/growth signal.

The complexity of the $\mathrm{NO}_{3}$ - effect on root development is further complicated by the fact that high $\mathrm{NO}_{3}{ }^{-}$concentrations $(50 \mathrm{mM})$ trigger an almost complete repression of the lateral root development (LRD). Abscisic acid (ABA) seems to be required for this effect, since the $\mathrm{NO}_{3}$ - inhibitory effect on LRD is reduced by mutating either the ABI4 or ABI5 genes [8].
Despite these striking examples, very little is known concerning the transcriptional gene regulatory networks involved in $\mathrm{NO}_{3}^{-}$/hormonal cross-talk. Here, as a step towards understanding such transcriptional co-control, we present a computational biology approach (Figure 1) designed to discover genes that are regulated in response to nitrate treatments across a range of background conditions. Further analysis identified a refined subset of gene clusters to be under the control of both $\mathrm{NO}_{3}{ }^{-}$and hormone signaling. We found that genes controlled both by hormones and $\mathrm{NO}_{3}{ }^{-}$are more responsive to $\mathrm{NO}_{3}{ }^{-}$and/or have a significantly higher level of baseline expression, than genes controlled by $\mathrm{NO}_{3}{ }^{-}$alone. This analysis lead us to generate a new hypothesis that hormone signals play a role in enhancing the effects of the $\mathrm{NO}_{3}$ - signal. Moreover, we identified cis-regulatory elements (CREs) in the promoters of these genes that are candidates for enhancing the nitrate-regulation of gene expression.

\section{Results \\ Bicluster analysis identifies a nitrate-responsive "biomodule"}

In a previous study, meta-analysis of transcriptomes of $\mathrm{NO}_{3}{ }^{-}$treated plants revealed that gene responses to nitrogen were very context-dependent, and only a very small number of core genes are regulated by $\mathrm{NO}_{3}{ }^{-}$in a contextindependent manner [2]. The underlying rules of such coordination/context dependence between signals had recently been proposed at a genome wide level concerning the interaction of carbon, nitrate, and light [3]. Moreover, in light of the context dependent nature of the $\mathrm{N}$ response, mono-dimension clustering algorithms will miss genes that are co-regulated by $\mathrm{N}$ across a subset of treatment conditions. By contrast, an approach also known for decades [24] called biclustering can be used to identify nitrate responsive genes that are co-regulated, as a group, in response to a subset of nitrogen treatments across a matrix of meta-data (Figure 1) [25], likely susceptible to tackle the context dependence response to $\mathrm{NO}_{3}^{-}$. Thus, detected biclusters are subsets of the studied genes exhibiting consistent patterns over a subset of N-treatment conditions. Such sets of genes would not be found using mono-dimension clustering approaches, which require that the genes in the cluster behave the same across all treatments. We used this biclustering method to analyze five microarray data sets from N-treatments of Arabidopsis generated by three different laboratory groups: the Crawford lab [26,27] (16 Affymetrix chips including controls), the Stitt lab [28] (14 Affymetrix chips including controls) and the Coruzzi lab [29,30] (46 Affymetrix chips including controls). This combined meta-data set resulting from $\mathrm{N}$-treatments corresponded to a total of 76 microarray chips with controls [For details see Additional File 1]. 


\section{A}

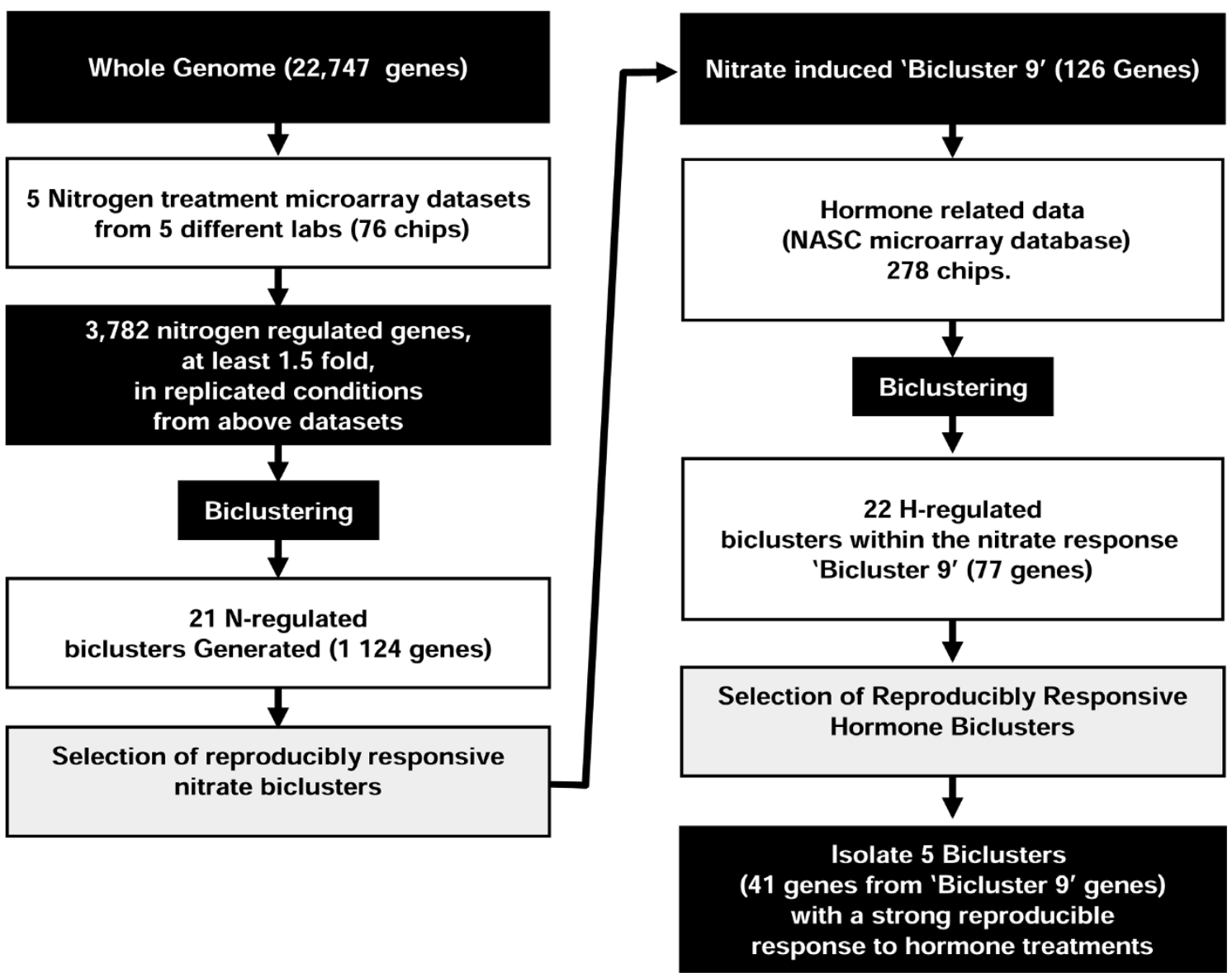

B

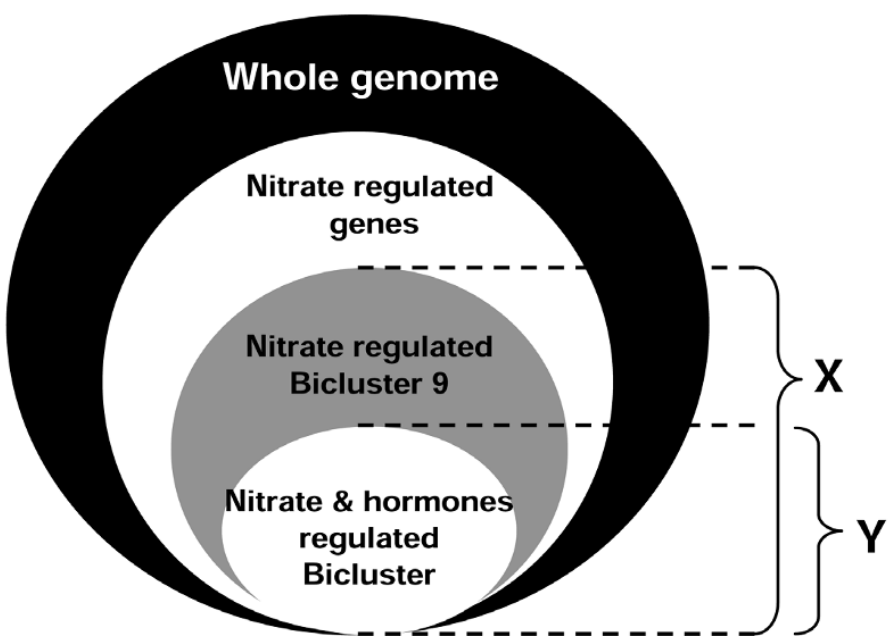

Comparisons between coregulated genes by nitrate $(X)$, and by nitrate and hormones (Y). $\rightarrow$ Infers Nitrate/Hormones relationships

Figure I

Schematic representation of the in silico strategy used to decipher a N/hormone crosstalk module. (A) The strategy was to discover via sequential biclustering filtering stages, co-regulated genes in response to: i) $N$ treatments, and also ii) hormone treatments. (B) This delimitation of gene groups (whole genome, $\mathrm{NO}_{3}^{--}$-regulated, Bicluster $9 \mathrm{NO}_{3}^{-}-$-regulated and $\mathrm{NO}_{3}$-/hormone co-regulated) and the comparison of their behavior allowed us to hypothesize how $\mathrm{NO}_{3}{ }^{-}$and hormonal signaling pathways are connected in gene networks. 
To identify N-regulated genes in this meta-dataset, we first used a filtering step that consisted of selecting genes that are significantly regulated by at least one $\mathrm{N}$-treatment across the various data sets (for filtering conditions see Methods, Figure 1). We found 3,782 such genes under the control of nitrogen in at least one of the considered $\mathrm{N}$ treatment conditions. This gene list was then used to generate 21 biclusters (containing 1,124 genes) using the SAMBA algorithm as implemented in the Click and Expander software package [31,32] (Figure 2). In order to identify whether the N-regulated biclusters had biological significance, we used the BioMaps analytical tool [30] to determine significantly over-represented functional categories using the MIPS annotation [33] in each of the $21 \mathrm{~N}$ biclusters generated [Additional File 1]. Significant overrepresentation was determined based on a p-value that passed a 5\% False Discovery Rate (FDR) cutoff (see Methods). Of the $21 \mathrm{~N}$-responsive biclusters, we selected the bicluster \# 9 (N-bicluster 9) for further investigation, based on the following criteria: i) genes in bicluster 9 show a reproducible response to N-treatment across several microarray datasets from several different studies (Figure 2), ii) the annotation of genes in N-bicluster 9 suggests that the genes in this bicluster have an important biological function since it comprises genes from all the known steps of $\mathrm{N}$-uptake and $\mathrm{N}$-assimilation (Table 1) [N-bicluster 9 gene list is provided in Additional file 1], and iii) N-bicluster 9 contained significant overrepresentation of MIPS functional categories spanning Amino Acid Metabolism, Carbohydrate Metabolism, and Transported Compounds, suggesting that the underlying regulatory mechanism serves to coordinate systems-wide responses to N (see Table 1). Here, it is noteworthy that this bicluster gathers relevant gene functions. As a matter of fact this coordination of a group of gene involved in the same functions can be designated as a "biomodule" [34-36]. Thus in this context, we used this terminology in the rest of our work.

To determine the connectivity between the genes in $\mathrm{N}$ bicluster 9, we queried the Arabidopsis multinetwork as described in [30] using the Virtual Plant software package http://www.virtualplant.org. The Arabidopsis multinetwork is a model that integrates information for gene interactions based on a variety of data including: Arabidopsis metabolic pathways, known protein:protein, protein:DNA, miRNA:RNA interactions, and predicted protein:protein and protein:DNA interactions [30]. From the network analysis of 126 genes in N-bicluster 9, a network comprised of information from metabolic and protein:protein connections included 179 nodes (52 genes and 127 metabolites) linked by 261 functional relationships (Figure 3). To test whether this level of connectivity was greater than expected by chance, we computed a pvalue by comparing this network to networks generated from a collection of genes of the same size, randomly sampled from the 22,746 genes present on the full genome chip ( $\mathrm{p}$-value $<0.0001$ ), computed as described in [37]. Thus, this analysis confirms that the 126 genes in N-bicluster 9 display a significant level of connectivity, providing added support that the biclustering approach has identified a biologically functional regulatory module or "biomodule" [34-36].

\section{The genes in the $\mathbf{N}$-bicluster 9 "biomodule" are induced by nitrate as a signal}

Here, we asked which $\mathrm{N}$-signals were involved in mediating the regulation of genes in N-the bicluster 9 biomodule. Nitrogen-responsive genes are known to be regulated by various endogenous and external nitrogen signals. For example, nitrate itself as been identified as a signal that regulates a large number of genes genome-wide [27]. In specific examples, nitrate can act as an inducer and a repressor of NRT2.1, which codes for a major component of the nitrate high affinity transport system [21,22,38]. Moreover, N-reduced metabolites such as $\mathrm{NH}_{4}{ }^{+}$, and organic forms of nitrogen (glutamine or glutamate) have been shown to also control gene expression, again at a genome-wide level $[39,40]$, which was also demonstrated in specific examples $[38,41]$. Because $\mathrm{NO}_{3}^{-}$is quickly assimilated into $\mathrm{N}$-reduced and organic-N compounds, we tried to elucidate which form of nitrogen regulates the expression of genes in N-bicluster 9. For this, we mined Affymetrix microarray data obtained from nitrate treatments of a nitrate-reductase T-DNA double mutant knockout from Wang et al [27], which was not included in the biclustering data set. This microarray data set was derived from wild-type (WT) and nitrate reductase (NR) null mutant Arabidopsis plants treated with $\mathrm{KNO}_{3}$ for 2 hrs. The NR double mutant is a T-DNA knockout mutant that is deficient in both structural genes encoding nitrate reductase (nia1 and nia2) and is therefore unable to reduce nitrate to downstream forms of nitrogen [27]. Thus, any genes that respond to nitrate in wild type and the NR double mutant are likely to be controlled by nitrate itself. We found that genes in the N-bicluster 9 biomodule are regulated in response to nitrate, since their nitrate responsiveness is preserved in the nia1/nia2 NR double mutant at levels identical to wild-type (Figure 4).

\section{Identification of nitrate/hormone responsive biclusters}

As stated above, the N-regulation of the bicluster 9 "biomodule" appears to have biological relevance as it contains genes covering all steps in the $\mathrm{N}$-uptake/assimilation pathway, and genes integrating the regulation of genes in $\mathrm{N}$-metabolism with other related metabolic processes including C-metabolism and Energy. As many of the genes in these pathways have been shown to be under control of other hormones [7,42,43], we hypothesized that hormonal control might play a role in the regulation 


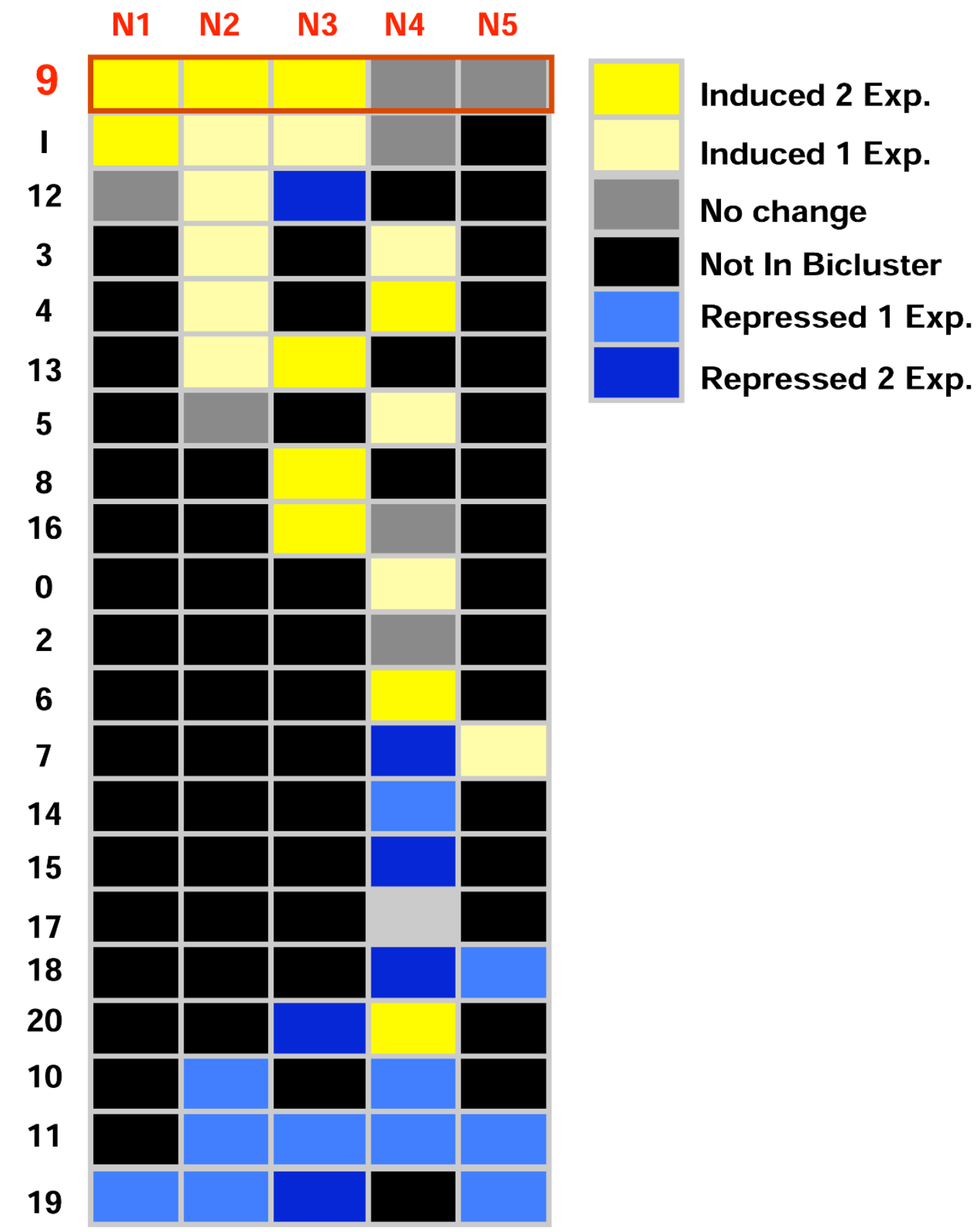

Figure 2

Identification of 2 I $\mathbf{N}$-responsive biclusters: Nitrogen-responsive genes sets identified across subsets of $\mathbf{N}$ microarray meta-data. Heatmap of the responsive conditions of $\mathrm{N}$-biclusters. The colors in the heatmap represent the kind of regulation (induced/depressed) and the degree of reproducibility for each data set captured in the N-biclusters. NI to N5 represent the data sets from 3 different labs. NI:(Wang et al., 2003); N2: (Wang et al., 2004); N3: (Scheible et al., 2004); N4: (Palenchar et al., 2004); N5 (Gutierrez et al., 2007). The details of the experimental conditions of these data set is described in Additional File I. N-bicluster 9 had the greatest degree of reproducibility over the greatest number of experiments. 
Table I: Over-represented functional categories in N-bicluster 9

\begin{tabular}{|c|c|c|c|}
\hline Term & Observed Frequency \% & Expected Frequency \% & P-value \\
\hline ENERGY & $14.30 \%$ & $1.50 \%$ & I.99E-II \\
\hline pentose-phosphate pathway & $4.80 \%$ & $0.10 \%$ & 3.13E-08 \\
\hline metabolism of energy reserves (e.g. glycogen, trehalose) & $3.20 \%$ & $0.10 \%$ & 0.00073 \\
\hline glycolysis and gluconeogenesis & $5.60 \%$ & $0.60 \%$ & 0.00027 \\
\hline METABOLISM & $21.40 \%$ & $6.50 \%$ & $9.80 \mathrm{E}-07$ \\
\hline C-compound and carbohydrate metabolism & $13.50 \%$ & $2.80 \%$ & $2.62 \mathrm{E}-06$ \\
\hline amino acid metabolism & $6.30 \%$ & $0.90 \%$ & 0.00059 \\
\hline assimilation of ammonia, metabolism of the glutamate group & $4.00 \%$ & $0.20 \%$ & 5.35E-05 \\
\hline nitrogen and sulfur metabolism & $4.80 \%$ & $0.30 \%$ & 4.35E-05 \\
\hline TRANSPORTED COMPOUNDS (SUBSTRATES) & $5.60 \%$ & $1.10 \%$ & 0.0161 \\
\hline
\end{tabular}

This table indicates the functional terms that are over-represented in N-bicluster 9 vs. the whole genome using BioMaps with a $5 \%$ FDR cutoff to determine the statistical significance of $p$-values (see Methods for approach). The frequency of these terms in the functional annotation of the genes from $\mathrm{N}$-bicluster and the $\mathrm{p}$-value generated by BioMaps are indicated.

of the genes in the N-bicluster 9 biomodule. To test this hypothesis, and to uncover the possible mechanistic basis for nitrate/hormome signaling interactions, we performed an in silico analysis of $\mathrm{N}$-bicluster 9 gene regulation in response to hormones. For this analysis, we constructed a meta-data matrix of microarray experiments from the NASC repository (Nottingham Arabidospsis Stock Center, [44]) covering all available hormone and hormone inhibitor treatment experiments (including auxin, abscisic acid, ethylene, cytokinin, brassinosteroids, giberellic acid and jasmonic acid). We included all data sets having replicates and a relative control (see Methods). The data were converted to a $\log$ base 2 ratio of treatment/control, and biclustering was used to identify sets of genes co-regulated under various hormone treatments. Biclustering of the 126 genes in the N-bicluster 9 biomodule over the hormone meta-data set generated 22 hormone biclusters referred to as $\mathrm{N} / \mathrm{H}$-biclusters (Nitrogen/Hormone responsive). These $\mathrm{N} / \mathrm{H}$ biclusters encompass 77 genes contained within $\mathrm{N}$-bicluster 9 [see Additional File 1 for a complete list of N/H-biclusters]. Each of these N/H biclusters has an average number of 8 genes with extensive overlap between several N/H biclusters. These results show that 77 of the genes (out of 126) in N-bicluster 9 are reproducibly regulated by both nitrate and hormone treatments. Further the fact that these genes overlapped between $\mathrm{N} / \mathrm{H}$ biclusters suggested that they may be responsive to several different types of hormone treatments. The $22 \mathrm{~N} / \mathrm{H}$-biclusters were classified according to filtering criteria described in Methods section (Table 2). Out of the $22 \mathrm{~N} / \mathrm{H}$-biclusters, five biclusters which showed the most extensive and reproducible responses to hormones were selected for further analysis (Figure 5). The metabolic and functionally interacting genes contained in these $\mathrm{N} /$ Hormone biclusters are highlighted in the $77 \mathrm{~N} / \mathrm{H}$ responsive genes in the network view of the N-bicluster 9, as depicted in Figure 3.

The analysis of the N/Hormone biclusters (biclusters 1, 6 , $16,19,20)$ revealed that cytokinin and ABA are the main hormone treatments under which the $\mathrm{NO}_{3}^{-}$regulated genes from $\mathrm{N}$-bicluster 9 are co-regulated (Figure 3 and 5). N/H-biclusters 1 and 19 are both mainly driven by ABA treatments, although their respective regulation is in opposing directions (induced vs. repressed). N/H-biclusters 6,16 , and 20 are comprised of genes almost exclusively regulated in response to cytokinin treatment (Figure 5 ). Together, our results suggest that the coordinated regulation of these genes to nitrate as well as cytokinin or ABA may be part of a regulatory network that mediates the responsiveness of these genes.

\section{Functional interactions within the nitrate/hormone biclusters}

As all $\mathrm{N} / \mathrm{H}$-biclusters were derived from the 126 genes contained in N-bicluster 9, we used a modified version of BioMaps analysis to determine which if any of the five selected N/H-biclusters were enriched for specific MIPS functional categories (see Methods). This analysis demonstrated that $\mathrm{N} / \mathrm{H}$-biclusters 1, 16 and 19 had at least one over-represented MIPS category, when compared to Nbicluster 9 [see Additional File 1]. The most significantly over-represented categories from these $\mathrm{N} / \mathrm{H}$-biclusters are genes involved in metabolic pathways, suggesting that this $\mathrm{NO}_{3}-$ /Hormone "crosstalk" may be directed towards the coordinate regulation of genes in interconnected metabolic pathways (see Network View of N-bicluster 9). Further, genes from $\mathrm{N} / \mathrm{H}$-bicluster 1 have several additional categories over-represented including Energy, Pentose phosphate pathway and Photosynthesis.

\section{Elucidation of a hormone "enhancement" of gene nitrate responsiveness}

With the aim of elucidating the mechanisms which mediate differences in regulation between genes that are controlled by $\mathrm{NO}_{3}$ - only $v$ s. genes that are co-regulated by $\mathrm{NO}_{3}{ }^{-}$and hormones, we analyzed the expression of the genes $\mathrm{N}$-bicluster 9 and $\mathrm{N} / \mathrm{H}$ bicluster in the NR double mutant data set [27]. This analysis uncovered a strong and 


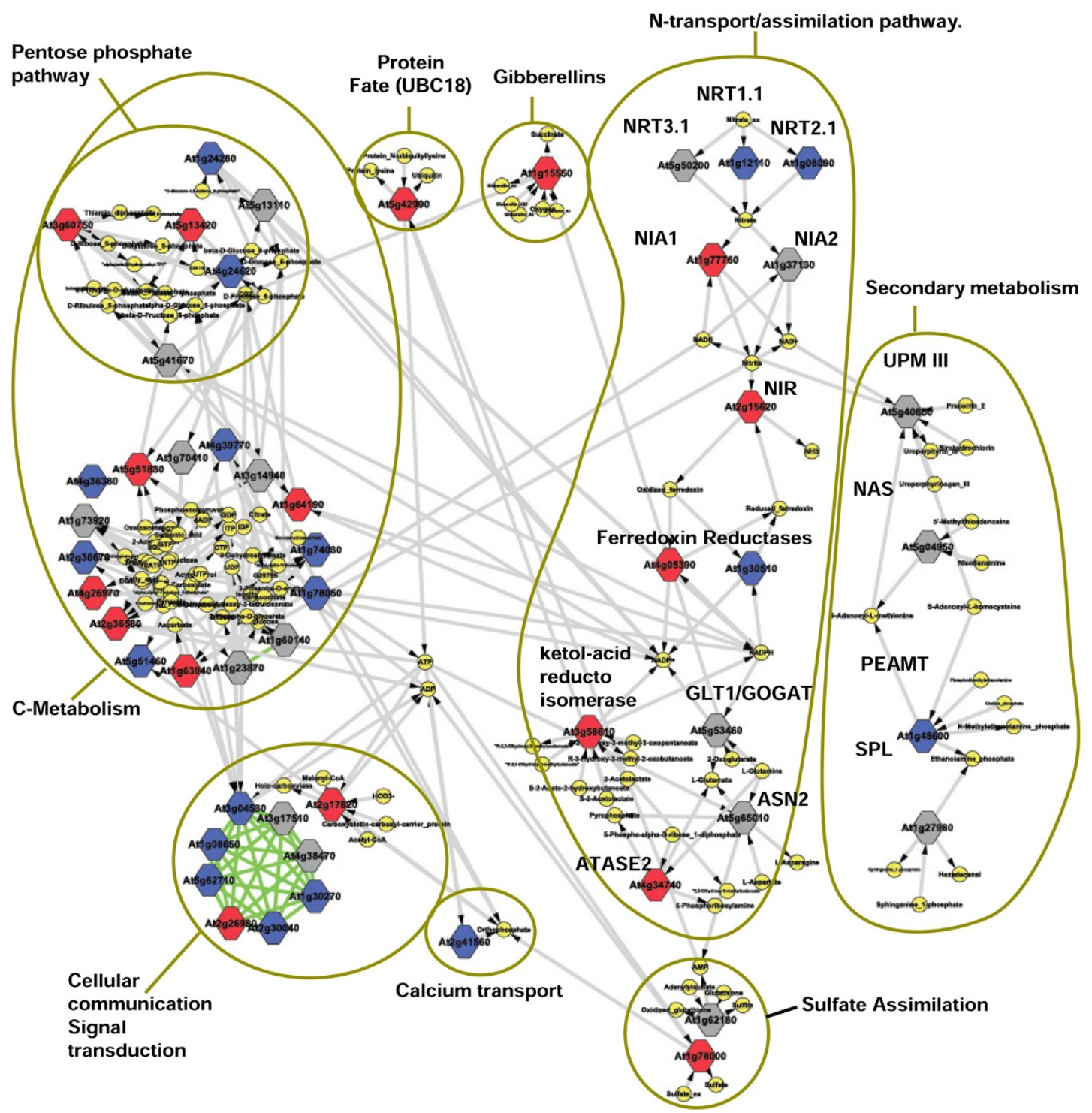

Figure 3

N-bicluster 9 gene network: A highly connected network of biologically related gene functions. The metabolic layer of information about gene connectivity in the Arabidopsis Multinetwork [30] was queried with the 126 genes belonging to the N-bicluster 9 . Nodes represent genes (colored squares) and metabolites (yellow circles) connected by edges (metabolic interactions are colored in grey, protein:protein interactions are colored in green). Genes belonging to: i) $\mathrm{N}$-bicluster $\mathrm{NO}_{3}{ }^{-}$ exclusive genes are colored in blue, ii) Significant $\mathrm{N} / \mathrm{H}$-biclusters are colored in red, iii) Other $\mathrm{N} / \mathrm{H}$-bicluster are colored in grey. 


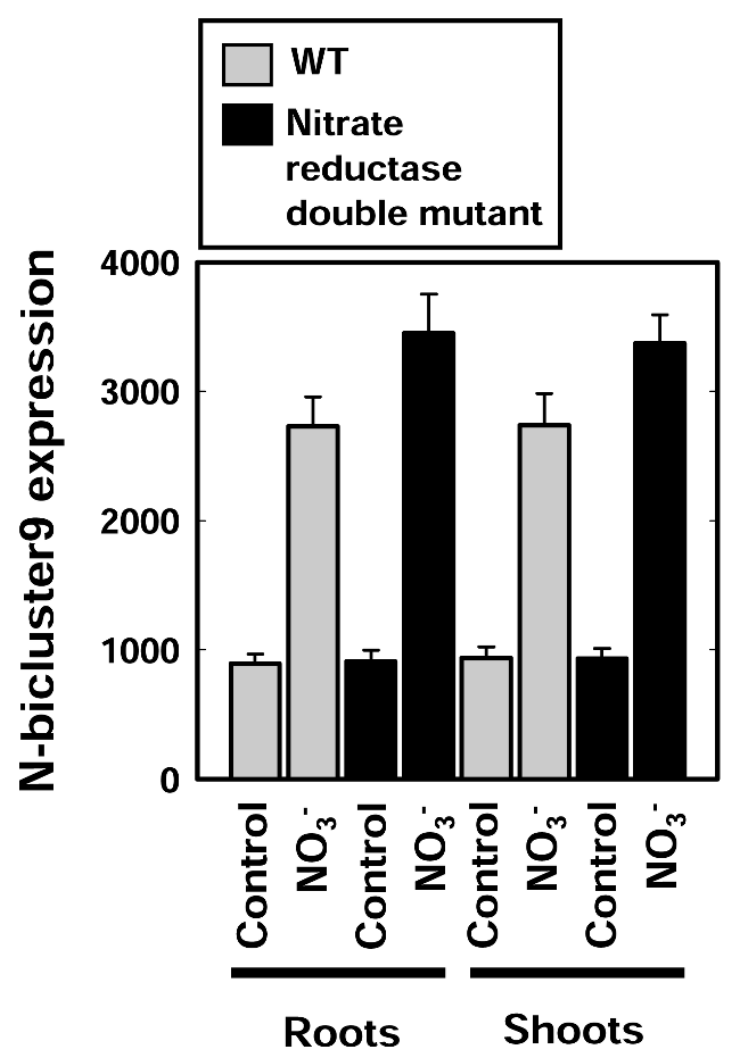

Figure 4

The 126 genes in $\mathbf{N}$-bicluster 9 are $\mathrm{NO}_{3}^{-}$regulated. Average raw MAS5 processed signal values for the 126 genes from $\mathrm{N}$-bicluster 9 in the nitrate reductase double mutant data [27]. Values in these plots indicate the average expression for each condition taken from the nitrate reductase double mutant data set where plants were treated with $\mathrm{KNO}_{3}$ or an equal concentration of $\mathrm{KCl}$ (Control).

unexpected difference between: a) the $\mathrm{NO}_{3}{ }^{-}$responsiveness of genes in all of the five $\mathrm{N} / \mathrm{H}$-biclusters $v s$. b) genes from N-bicluster 9 that did not appear in any hormone bicluster (termed "N-bicluster 9 exclusive") (Figure 6) (see also informatic analysis scheme Figure $1 \mathrm{~B}$ ). Based on the analysis described below, genes belonging to N/H-biclusters $1,16,19$ and 20 are significantly more $\mathrm{NO}_{3}{ }^{-}$responsive as measured by the amplitude of expression in genes from N-bicluster 9 that do not fall into any N/H-bicluster (N-bicluster 9 exclusive genes) (see results of ANOVA, Table 2). Further, we validated that the enhanced nitrate responsiveness for the genes belonging to the $\mathrm{N} / \mathrm{H}$ biclusters, is exhibited not only in the NR double mutant data set, but also in the entire $\mathrm{N}$-treatment meta-data set used to build the N-biclusters [N1 to N5, see Additional File 1] (data not shown).
To quantify and statistically validate the regulation and nitrate-responsiveness of the genes in the $\mathrm{N} / \mathrm{H}$ biclusters in the NR double mutant data set (Figure 6), we modeled the expression of genes from these groups using the $l m$, summary.lm and ANOVA functions in [R] [45]. In this analysis the gene-expression response variable was modeled as a function of 4 explanatory-variable factors: i) Treatment, with 2 levels (nitrate treatment and control); ii) Tissue, with 2 levels (roots and shoots); iii) Genotype, with 2 levels (mutant (NR double mutant) and wild-type); iv) $\mathrm{N} /$ H-bicluster, with 6 levels (N/H bicluster 1, 6, 16, 19, 20 and N-bicluster 9 exclusive). To avoid any ambiguity between factor levels, overlapping genes from H-biclusters were removed from the analysis. The response variable (signal values) were taken from the normalized MAS5 data from the Wang et al, dataset [27] (These data were used to build Figure 6). In our ANOVA analysis, we started with an initial model that included main effects for each of the factors and an interaction term for the Treatment and $\mathrm{N} / \mathrm{H}$-bicluster factors. We simplified the model systematically in a step-wise procedure as outlined in Crawley [46] and fully described in Additional File 2. Briefly, our results from ANOVA analysis showed that the main effects of Tissue and Genotype factors were not significant (p-values of 0.13 and 0.94 , respectively). Further it revealed that the factor levels of $\mathrm{N} / \mathrm{H}$-biclusters were not all significantly different from each other. Specifically NHbicluster 1619 , and 20, in one hand, and 6 and N-bicluster 9 exclusive, in the other hand, were not significantly different from each other so that these levels could be combined into a single compound level. The final result of our simplification procedure was a model with main effects of Treatment (with 2 levels), N/H bicluster (with 3 compound levels), and an interaction term between $\mathrm{N} / \mathrm{H}$ bicluster and Treatment. The $\mathrm{R}$ code and output for this model simplification are fully available in Additional File 2.

Using this final model, we were able to show that the N/ $\mathrm{H}$ bicluster 1 level and the compound level for $\mathrm{N} / \mathrm{H}$ biclusters 16, 19 and 20 are both significantly different from the compound level of N/H bicluster 6 and N-bicluster 9 exclusive in both having a stronger baseline response and a stronger response to nitrate (see Figure 6). Taken together our combined bicluster analysis data from $\mathrm{N}$ treatment and hormone-treatment meta-datasets, leads us to propose a new hypothesis that hormone signaling (specifically ABA, and/or cytokinins which are represented in $\mathrm{N} / \mathrm{H}$ biclusters 1, 16, 19 and 20) may act as an enhancer of $\mathrm{NO}_{3}$ - signaling/induction. 
Table 2: $\mathrm{NO}_{3}$-/Hormone Response Interaction.

\begin{tabular}{lll}
\hline Description of Comparison & Coefficient Estimate & P-value \\
\hline N/H-bicluster I vs. Exclusive +N/H-bicluster 6 & 1721.4 & $4.08 \mathrm{E}-05$ \\
N/H-Bicluster I6, 19, 20 vs. Exclusive + N/H-bicluster 6 & 761.8 & 0.0099 \\
Treated vs. Control & 1290.1 & $5.82 \mathrm{E}-07$ \\
N/H-bicluster: Treated & 2190.2 & 0.00022 \\
N/H-Bicluster 16, 19, 20: Treated & 1011.9 & 0.01539 \\
\hline
\end{tabular}

Analysis of variance that examines the response to nitrate treatment of $\mathrm{N}$-bicluster 9 genes that fell into various hormone biclusters or failed to appear in a hormone bicluster. Coefficients and p-values in the simplest model that retained explanatory power. The gene-expression response variable is determined by main effects of Treatment (with 2 levels: control and treated), N/H bicluster (with 3 compound levels), and an interaction term between $\mathrm{N} / \mathrm{H}$ bicluster and Treatment. In this model, $\mathrm{N}$-bicluster 9 exclusive genes and $\mathrm{N} / \mathrm{H}$ bicluster 6 genes form an aggregate "control" group with no significant difference between them. A second, significantly different, aggregate group is comprised of genes in N/H-biclusters 16,19 and 20 . A third group includes genes from $\mathrm{N} / \mathrm{H}$-bicluster I only. The control level for the Treatment factor is $\mathrm{KCl}$. In this table each main-effect coefficient represents a difference in expression from the group comprised of $\mathrm{N}$-bicluster 9 exclusive and $\mathrm{N} / \mathrm{H}$ bicluster 6 genes under $\mathrm{KCl}$ treatment. The interaction term is over and above the main effects. For example, the difference between the mean expression of $\mathrm{N} / \mathrm{H}$-bicluster I genes under nitrate treatment and the mean expression of the control-group genes under control treatment $(\mathrm{KCl})$ is obtained by summing: the main effect of $\mathrm{N} /$ $\mathrm{H}$-bicluster I (I72I.4); the main effect of (nitrate) Treated (76I.8); and the term representing the interaction between N/H-bicluster I and Treated (2190.2).

\section{Identification of candidate cis-binding elements involved in the hormonal enhancing effect of the nitrate response and in silico validation}

In order to determine candidate cis-regulatory elements (CREs) involved in the proposed 'enhancing' effect of hormones on nitrate signaling, we first scanned the 3,000 bp parsed upstream promoter sequence of the genes in $\mathrm{N}$ bicluster 9 for known transcription factor binding sites using a DNA pattern search tool [47]. We next determined the over-representation of these CREs in the $126 \mathrm{~N}$-bicluster 9 genes using the Fisher Exact Test (see Methods). Based on this analysis, 23 CRE elements were found to be significantly over-represented in N-bicluster 9, compared to the genome-wide frequency of these elements. These CREs could potentially be involved in nitrate responses, or in a yet to be defined signal (or complex of signals) controlling this gene cluster as a whole (Table 3). Using a similar approach we tested for a significant difference in the CRE frequency for these CREs between two groups: one containing the N/H bicluster 1, 16, 19 and 20 genes and the other containing the $\mathrm{N}$-bicluster 9 exclusive (background). N/H bicluster 6 was removed from this and all subsequent analysis as it was shown to not be significant in the previous ANOVA and contained very few genes ( 2 genes) when overlapping genes were removed. This analysis revealed that 2 CREs, HSE element [48] and E2F element [49]. These two CRE elements are significantly over-represented in the N/H biclusters (See Table 4) analyzed as a group compared to their frequency within the subset of N-bicluster 9 genes not present in any of the $\mathrm{N} /$ $\mathrm{H}$-biclusters (termed $\mathrm{NO}_{3}$ - exclusive). The specific overrepresentation of these CREs in the $\mathrm{N} / \mathrm{H}$ biclusters implicates them as potential candidates to be involved in the cross-talk between hormone and $\mathrm{NO}_{3}^{-}$response. The known physiological roles of the E2F and HSE CREs are discussed below.

\section{Discussion \\ Biclustering identifies a "biomodule" of biologically related nitrate-regulated genes involved in metabolism and signal transduction}

In a previous meta-analysis of nitrate-regulated genes, we demonstrated that a very small number of genes are nitrate regulated across a variety of background conditions, while the vast number of nitrate-regulated genes are regulated in a context-dependant manner [2]. This observation suggests that the $\mathrm{NO}_{3}{ }^{-}$signaling pathway is also under the influence of other (as yet) unidentified controls. Taking this observation as a starting point, we decided to use biclustering technique: an approach that clusters both genes and treatments, as a tool to discover genes that are co-regulated by nitrate across a wide variety of background conditions corresponding to a subset of the meta-data analysis. This biclustering approach allowed us to uncover a "biomodule" of $126 \mathrm{NO}_{3}$ - regulated genes that are related in expression pattern and in biological function (N-bicluster 9, Figures 2 and 3, Additional file 1, table s2). Indeed, as a group, the genes in $\mathrm{N}$ bicluster 9 comprise a set of 52 metabolic genes including, for example, all steps in the pathway of nitrate uptake \& reduction (NRT1.1, NRT2.1, NRT3.1, NIA1, NIA2, NIR), as well as genes involved in $\mathrm{N}$-assimilation into organic form (GDH1, ASN2 and GLT1). In addition, the N-bicluster 9 also contains significant overrepresentation of genes involved in Energy, Nitrogen and Carbon metabolism (Table 2). This strong functional coherence of the genes in $\mathrm{N}$-bicluster 9 is illustrated by the interactions between 52 genes in the metabolic/protein interactions shown in the subnetwork (Figure 3).

It is noteworthy that the concept of the 126 genes in bicluster 9 constituting a "biomodule" in our study is comparable to ideas that have been already developed by 


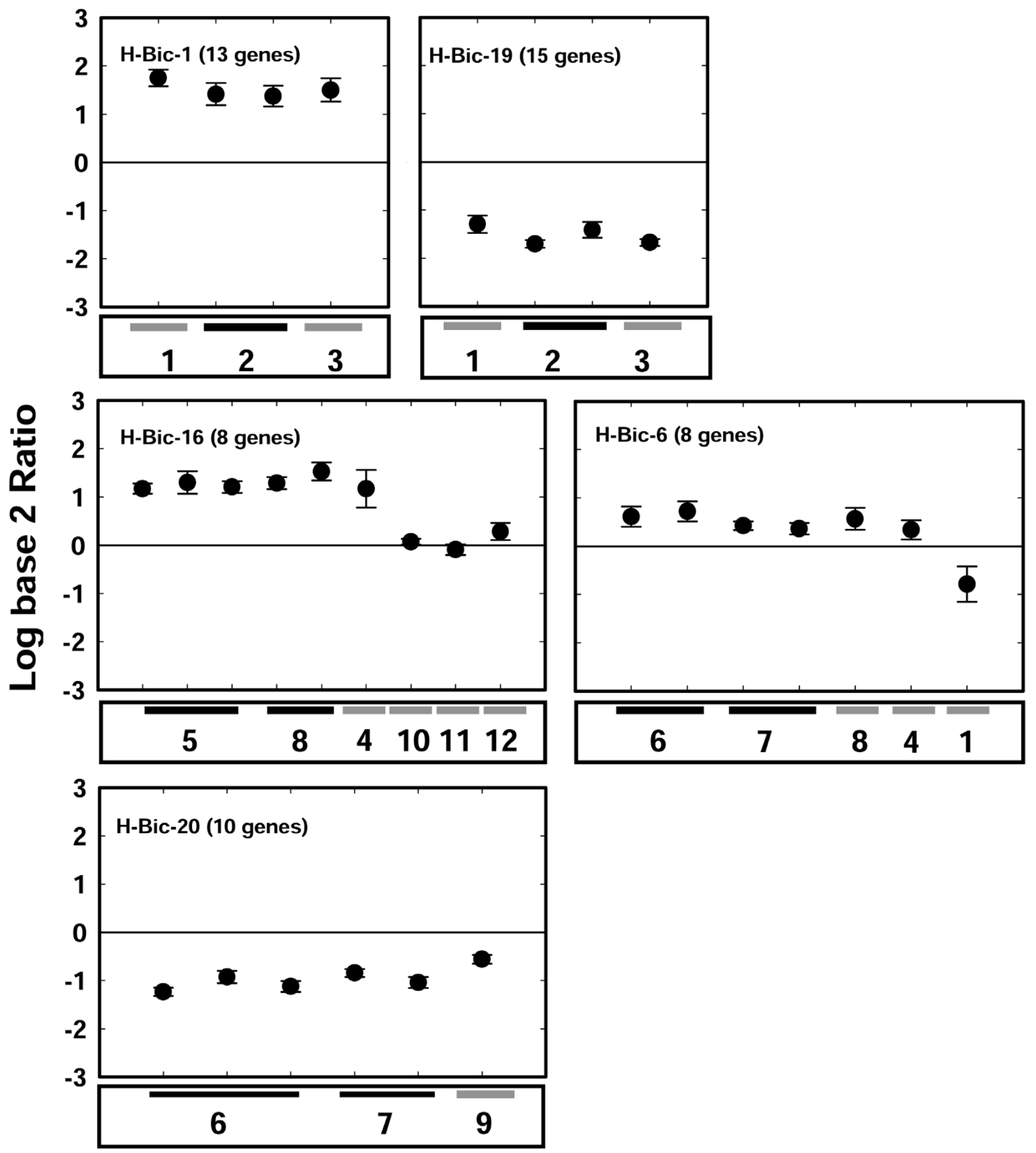

Figure 5 (see legend on next page) 
Figure 5 (see previous page)

Hormone responsiveness of the five selected $\mathbf{N}$ /H-biclusters from $\mathbf{N}$-bicluster $\mathbf{9}$. Centroid plots of the expression patterns for genes across the 5 significant (> 50\% reproducibility; > I.5 fold change) N/H-biclusters. Black bars below the plots indicate replicate experiments and grey bars indicate singleton experiments. N/H-biclusters I and 19 show a strong response to $A B A$ treatment during seed imbibition (induction and repression respectively), N/H-biclusters 16 and 6 show an induction to cytokinin in roots and shoots of mutant and wildtype plants respectively. $\mathrm{N} / \mathrm{H}$-bicluster 20 shows a strong depression due to cytokinin in root tissues of mutant and wild type plants. Treatments are taken from the NASC data set: I- Brassinolide I0 nM 3 hours (Seedlings), 2- ABA $3 \mu$ M 24 H (during Seed Imbibition), 3- ABA $30 \mu M 24$ H (during Seed Imbibition), 4- Zeatin $20 \mu M$ I H (Seedlings), 5- Zeatin $20 \mu \mathrm{M}$ । H (Shoots), 6- Zeatin $20 \mu \mathrm{M}$ । H (Roots), 7- arr /0//2 Zeatin $20 \mu \mathrm{M}$ I H (Roots), 8- arr I0/ I 2 Zeatin $20 \mu \mathrm{M}$ I H (Shoots), 9- AtIPT8/pga22 (Seedlings), I0- ga I-5 GA3 I $\mu$ M 0.5 H (Seedlings), I I- IAA I $\mu$ M 0.5 H (Seedlings), I2- IAA I $\mu$ M I H (Seedlings).

others in the field of systems biology. For instance, i) Baliga et al. [50] state that "a biomodule is a group of proteins that execute a particular function", and ii) Bonneau et al. [51] also used a biclustering approach (cMonkey) to define "biologically meaningful biclusters". The conjunction of both above definitions match our concept/definition of a "biomodule".

As an insight into potential TFs that regulate the genes in this network, it is noteworthy that N-regulated bicluster 9 contains 17 transcription factors (based on AGRIS transcription factor annotation) whose regulation is by definition correlated with targets in N-bicluster 9, as well as with genes from other functional and unknown categories. $\mathrm{N}$ bicluster 9 also contains other regulatory genes potentially involved in signal transduction such as kinases or phosphatases $(6 \%$ of the genes from this N-bicluster fall into this category) (Table 1$)$.

\section{Hormones enhance the $\mathrm{NO}_{3}$ - responsiveness of genes within the bicluster 9 biomodule: what are the physiological consequences?}

To identify potential regulatory mechanisms for the $\mathrm{NO}_{3}$ responses of these genes to by other stimuli, we examined the regulation of the 126 genes in N-bicluster 9 across a metadata set of hormone microarrays. This was done in order to try to understand whether these genes, or subsets of these genes, are coregulated by hormones as well. Hormone treatments have been previously shown to have strong interactions with nitrogen signaling [5]. This analysis identified a subset of 77 genes in N-bicluster 9 that also cluster together across a subset of hormone treatments. The position of these 77 genes present in the N/ Hormone biclusters are shown in the context of the metabolic/protein interaction network presented in Figure 3. This view demonstrates a strong potential effect of diverse hormonal controls on the level of response of $\mathrm{NO}_{3}{ }^{-}$-controlled metabolic processes [See Figure 3 color coding for nodes: Red squares = significant $\mathrm{N} / \mathrm{H}$-bicluster genes (genes from N/H-biclusters 1, 16, 19 and 20), Blue squares $=$ genes controlled only by $\mathrm{NO}_{3}{ }^{-}$and not co-regulated by hormone treatments, based on results of hor- mone biclustering, Grey squares = non-significant N/Hbicluster genes controlled by hormones (i.e. no reproducible hormone response in $\mathrm{N} / \mathrm{H}$ biclusters, see Methods)]. This hormonal control of nitrate-regulated genes represents a potential mechanism to fine tune and co-ordinate response levels of genes in a biomodule so that metabolic processes (here $\mathrm{N}$-assimilation, carbon metabolism, and signaling components) can be regulated according to the growth rate of the plant. This is consistent with the observations made for phosphate [52,53], sugar [54], sulfate [55], and iron metabolism [56]. In all of these previous studies, when the hormone receptor is mutated, the response of genes to the nutrient under investigation is maintained, but the hormone response of the same genes is abrogated. This implies that hormonal control of nutrition pathways has a broad effect and controls metabolism as a whole, and is distinct from nutrient signaling. Our current work supports this view and also goes a step further. Indeed, our systems approach has enabled us to derive the hypothesis that hormone signals can interact with $\mathrm{NO}_{3}$ - signals to enhance the responsiveness of genes, and we have performed and in silico test of this hypothesis. This hypothesis is based on the finding that genes controlled by $\mathrm{NO}_{3}$ - only, were shown to be less responsive to $\mathrm{NO}_{3}$ - than genes under the control of $\mathrm{NO}_{3}{ }^{-}$and hormones (Figure 6, Table 2). This kind of interaction has to our knowledge never been reported, and is a particularly novel aspect of for the effect of hormones as they relate to $\mathrm{NO}_{3}$ - induction. Although the effect of external hormone supply on genes belonging to $\mathrm{NO}_{3}{ }^{-}$assimilation pathway or sensing system has already been documented, our results propose a new dimension of interaction at the transcriptional level between hormonal and $\mathrm{NO}_{3}{ }^{-}$signaling. The existence of specific links between different nutrient and hormonal signals reported herein is also of particular interest and deserves further investigation.

\section{Putative roles of the E2F and HSE Cis Regulatory Elements (CRES) in mediating cross talk between nitrate and hormone signaling}

Our study has identified two putative regulatory elements that are over-represented in the four significant $\mathrm{N} / \mathrm{H}$ - 


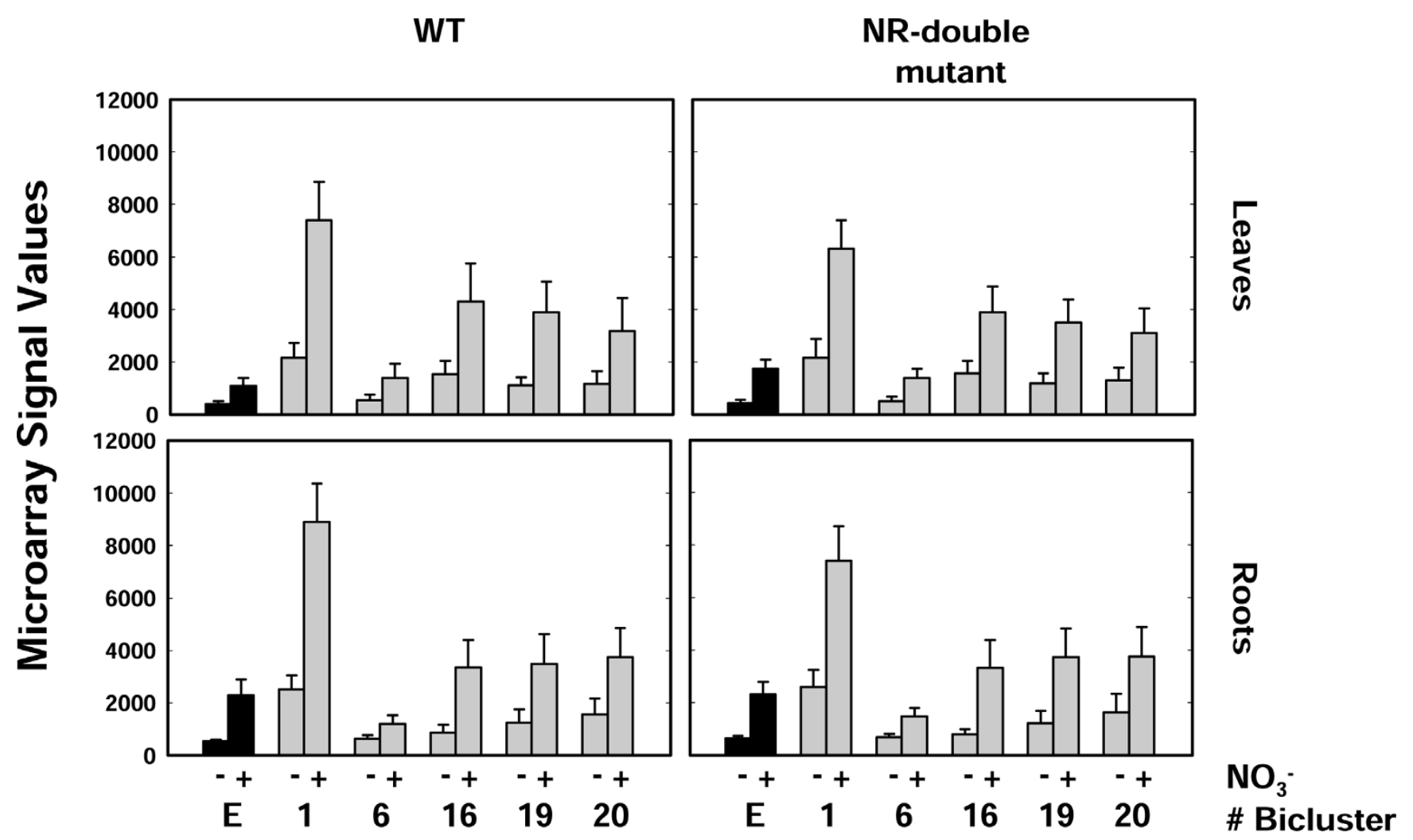

Figure 6

Changes in $\mathrm{NO}_{3}{ }^{-}$responsiveness for genes in significant $\mathbf{N} / \mathbf{H}$ biclusters vs. $\mathbf{N}$-bicluster $\mathbf{9}$ exclusive genes. Histogram plots of average expression over $\mathrm{NO}_{3}$ - treatment conditions in both WT and NR double mutant microarray data showing the nitrate responsiveness of genes that were present in significant hormone biclusters and genes that were not present in any $\mathrm{N} / \mathrm{H}$-bicluster ( $\mathrm{N}$-bicluster 9 exclusive $(\mathrm{E})$ ), data indicates root and shoot responses in WT and NR double mutant plants). Comparison between treatment and control across the different groups indicates a clear difference in both the baseline expression level and average response to nitrate for $\mathrm{N} / \mathrm{H}$-biclusters I, 16, 19 and 20 and was confirmed with ANOVA (see text). (+) $\mathrm{KNO}_{3}$ treatment, (-) $\mathrm{KCl}$ treatment.

biclusters identified by ANOVA (Table 2). To identify the potential role of such elements in mediating the hormone enhancing effect on nitrate responsiveness, we performed an in silico analysis aiming at deciphering the potential effect of each candidate binding site. By removing all genes from N-bicluster 9 exclusive gene list that contained these CREs (E2F and HSE), we were able to "virtually" examine their respective role in the enhancement of the baseline and $\mathrm{NO}_{3}-$ response by comparing these genes to genes from significant N/H-biclusters 1, 6, 16 and 20. The analysis demonstrated that E2F and HSE CREs are potentially involved in the hormonal enhancing effect of expression of these $\mathrm{NO}_{3}-$ responsive genes (Table 4, 5, and 6). To date, the heat shock elements (HSE) were not shown to be involved in the control of $\mathrm{N}$-regulated genes though their role in Arabidopsis in the transcriptional control of responses to heat stress has been extensively studied [57]. However, a heat shock transcription factor $H s f A 9$ has been shown to be under hormonal control in seeds (ABA through ABI3) [58]. This observation leads to the tentative hypothesis that heat shock elements could potentially be involved in conveying a hormonal signal. Moreover, to further have insight into the HSF/hormonal connection we ran a Sungear [59] analysis to decipher if 
Table 3: Over-represented known CREs in N-bicluster 9.

\begin{tabular}{llll}
\hline Cis Regulatory Element & \% Present in Whole Genome & \% Present in N-bicluster 9 & P-value \\
\hline Boxll & $49.32 \%$ & $66.67 \%$ & $6.90 \mathrm{E}-05$ \\
RAVIA & $84.00 \%$ & $94.44 \%$ & $1.94 \mathrm{E}-04$ \\
Wbox & $80.83 \%$ & $92.06 \%$ & $3.40 \mathrm{E}-04$ \\
MYB2CONSENSUSAT & $63.96 \%$ & $78.57 \%$ & $3.43 \mathrm{E}-04$ \\
RY_repeat & $5.36 \%$ & $13.49 \%$ & $4.09 \mathrm{E}-04$ \\
ebox & $86.24 \%$ & $95.24 \%$ & $5.87 \mathrm{E}-04$ \\
DPBFI\&2_binding_site_motif & $64.32 \%$ & $77.78 \%$ & $9.66 \mathrm{E}-04$ \\
ARF & $45.03 \%$ & $59.52 \%$ & 0.001096 \\
AtMYC2_BS_in_RD22 & $44.10 \%$ & $57.94 \%$ & 0.001509 \\
MYB4 & $72.72 \%$ & $84.13 \%$ & 0.001727 \\
Bellringer/replumless/Pennywise BSI IN AG & $42.04 \%$ & $55.56 \%$ & 0.001932 \\
SV40 & $25.69 \%$ & $38.10 \%$ & 0.001954 \\
& & & \\
ATB2/AtbZIP53/AtbZIP44/GBF5BS in ProDH & $48.52 \%$ & $61.90 \%$ & 0.002188 \\
CCAI & $34.48 \%$ & $47.62 \%$ & 0.002400 \\
ABRE like & & & \\
AtMYB2 BS in RD22 & $26.46 \%$ & $38.10 \%$ & 0.004204 \\
T box & $16.57 \%$ & $26.19 \%$ & 0.005280 \\
LFY & $58.94 \%$ & $70.63 \%$ & 0.006024 \\
\end{tabular}

Results of a promoter sequence analysis of genes from N-bicluster 9 with the Fisher Exact Test used to determine CRE frequency overrepresentation in N-bicluster 9 . Over-representation of CREs was determined by comparing the frequency of these sites in N-bicluster 9 genes to the frequency in the whole genome as a background. Significance was determined using a 5\% FDR cut-off. Indicated in this table is the percentage of genes from the whole genome and $\mathrm{N}$-bicluster 9 that contain these elements and the respective $\mathrm{P}$-values for over-representation. $* \mathrm{P}$-values $0.0 \mathrm{I}-$ 0.05 ; **P-values $0.001-0.01$; ***P-values $<0.001$.

these factors are under any other hormonal controls. To do so, we queried gene annotation for HSF term. We found $21 \mathrm{HSF}$, and looked to see if they were found regulated by any hormone as reported by Nemhauser et al. [60]. Out of the $21 \mathrm{HSF}$ detected we found that $6(28 \%)$ are regulated by ABA ( 2 of which are also regulated by methyl-jasmonate), and 1 gene is regulated by cytokinins. This kind of co-regulation might further support the potential connection between HSF and hormonal signals.

E2F binding elements and the role of their associated transcription factors are still poorly understood in plants. However, what is known in plants as well as in other organisms is that these factors (considered in animals as oncogenes) are involved in the control of the cell cycle
$[61,62]$. Remarkably the role of E2F in the control of gene expression related to $\mathrm{N}$-assimilation has already been shown in Arabidopsis, providing an independent validation of our results. Vlieghe et al. [63] demonstrated that the over-expression of the E2Fa-DPa transcription factor leads to the induction of nitrate reductase (NIA2), glutamine synthetase (GS), glutamate synthase (GOGAT), and nitrite reductase (NIR) gene. It is noteworthy that all of these genes respond to both nitrate and hormonal signals in our analysis (Figure 3). Furthermore, several genes in the $\mathrm{N} / \mathrm{H}$ biclusters that are involved in C-metabolism are also mis-regulated in plants over-expressing E2FaDPa. Interestingly, E2F CREs were also identified in the nitrate reductase promoter of the green algae, Chlorella vulgaris. The protein binding activity at this site was vali-

Table 4: Over-represented CREs for 4 significant N/H-biclusters.

\begin{tabular}{llll}
\hline CRE Name & $\begin{array}{l}\text { P-value } \\
\text { (N/H-Bicluster vs. N-bicluster } \\
\text { 9 Exclusive) }\end{array}$ & $\begin{array}{l}\text { \% Present in N/H- } \\
\text { bicluster Genes }\end{array}$ & $\begin{array}{l}\text { \% Present in N-bicluster } 9 \\
\text { Exclusive Genes }\end{array}$ \\
\hline E2F & $0.0022^{* *}$ & $60.5 \%$ & $27.08 \%$ \\
$\mathbf{9}$ Genes
\end{tabular}

Results of a promoter sequence analysis of genes from 4 significant $\mathrm{N} / \mathrm{H}$ biclusters based on ANOVA with the Fisher Exact Test used to determine CRE frequency over-representation of in the collective gene list (38 genes) vs. $\mathrm{N}$-bicluster 9 exclusive genes. Indicated in this table are the p-values for over-representation, the frequency of these CREs in the $4 \mathrm{~N} / \mathrm{H}$ biclusters, the frequency of the same CREs in the N-bicluster 9 exclusive gene list and the frequency of these CREs in the full $\mathrm{N}$-bicluster 9 gene list. Based on the analysis of the 4 significant $\mathrm{N} / \mathrm{H}$-biclusters, only the $\mathrm{p}$-values for the HSE and E2F CREs were significant, indicating over-representation of these CREs (significance based on a $5 \%$ FDR cutoff). **P-values $0.00 \mathrm{I}-0.0 \mathrm{I}$ 
dated but was not dependent on nitrate in the media [64]. This confirms the idea that E2F CREs are involved in the interaction of the $\mathrm{NO}_{3}-$ response with other signals such as hormones and may be mediating crosstalk between these signals. Finally, the cell cycle is known to be an important target of hormonal signaling. For instance the Arabidopsis E2FC-DPB transcription factor was demonstrated to be involved in the control of the cell cycle. Also, cell division (monitored by CYCB1-GUS) in plants over-expressing E2FC-DPB was found to be less sensitive to auxin than cell division in wild types plants. This supports the hypothesis that E2F transcription factors are involved in mediating hormonal control of cell division [65].

\section{Conclusion}

In conclusion, our results suggest and highlight a significant level of control of $\mathrm{NO}_{3}$ - signaling by hormones. This control may allow plants to modulate biomodules of genes spanning $\mathrm{N}$ and $\mathrm{C}$ metabolism according to growthdependant hormone signals. The systems biology approach presented herein demonstrates the inference of relationships between signals a postriori using extensive microarray data sets $(76$ chips for Nitrogen +278 chips for hormones) to uncover new hypotheses for mechanisms underlying the much studied but poorly understood interactions between nutrient and hormone signaling. This in silico approach opens the door toward unraveling new biological concepts by systems analysis of existing microarray and other genome scale data sets within the public domain.

\section{Methods \\ Nitrogen Microarray Meta-Data set used for bicluster analysis}

Expression values for all genes within the Arabidopsis genome present on the Affymetrix chip were taken from published data on nitrogen treatments vs. controls for all the available experiments from the data sets published in:[26-28,30]. All microarray data used in this analysis was processed and normalized using Affymetrix Suite 5.0 or MAS5 Software (as implemented in the R statistical package [45] the two normalization Methods gave equivalent results. For biclustering analysis (see below), signal values were converted to log base 2 ratios with the treatment condition compared to its relative baseline condition (control). Genes with raw signal values less 100 in their treatment or control conditions in either replicate had their signal log ratio values replaced with a nonnumerical NA value which is ignored by the biclustering algorithm. Finally, Log 2 ratio data from the microarray data was analyzed to determine which genes in the genome were greater then 1.5-fold responsive in any pair of replicate experiments in this meta data set. The resulting list of 3,752 N-responsive genes was used for biclustering, as described below.

\section{Hormone Microarray Meta Data Analysis}

All hormone microarray data was taken from the MAS5processed NASC Microarray database (Nottingham Arabidopsis Stock Center [44]) data. Data was chosen based on annotation and experimental conditions that referred to a hormone or hormone inhibitor treatment vs. a relative control, with only replicated data used for biclustering analysis. A total of 19 data sets comprising 278 microarray experiments were compiled based on these criteria. The full list of data sets and the contributing number of microarrays from each data set is provided in Additional File 1. All hormone data with signal values of $<100$ had their signal values replaced with a non-numerical NA value. Further, all data was converted to log base 2 ratios prior to biclustering analysis. The 126 genes from N-bicluster 9 were biclustered over all hormone data as described (see below).

\section{Biclustering of Microarray Data}

Biclustering was performed using the SAMBA algorithm as described by [32] and as implemented in the CLICK and EXPANDER program [31]. Biclustering was performed using default parameters except as follows: amount of overlap allowed (50\%), gene coverage (set to cover all genes) and the number of genes expected (set to maximum number of genes in the data set). Biclusters that were used for further analysis were chosen based on genes being $\geq 1.5$ fold regulated across reproducible experiments and the presence of replicate experiments for $\geq 50 \%$ of the experiments.

\section{BioMaps Analysis of $\mathbf{N}$-biclusters}

BioMaps analysis of N-biclusters was performed as described in [30] as accessed via http://www.virtual plant.org. The program was run using the MIPS [33] annotation option for functional definitions. A 5\% FDR (False Discovery Rate) cut-off was computed using the R statistical package [45] to determine significant p-values.

\section{Modified BioMaps of N/Hormone Biclusters}

As N/H-biclusters were derived from N-bicluster 9, overrepresentation of MIPS [33] functional terms were determined using the Fisher's Exact Test as implemented in the $\mathrm{R}$ statistical package [45] to compare the proportions of genes from $\mathrm{N} / \mathrm{H}$-biclusters containing a MIPS term vs. the proportion of genes from N-bicluster 9 not in N/H biclusters containing that same term.

\section{Multinetwork Analysis of Bicluster 9}

To understand the relationships among the 126 genes from N-bicluster 9, the Arabidopsis multinetwork analysis tool was used [30] as accessed by http://www.virtual plant.org. This network contains many validated connections for gene interactions in the Arabidopsis genome. Network interactions were visualized using Cytoscape [66]. 


\section{Computing the False Discovery Rate (FDR)}

An FDR control method was used to determine a significance cutoff for $\mathrm{p}$-values. This value was computed using a script written for the R statistical package [45]. This script was derived from the Storey and Tibshirani method [67] which determines a cut-off based on the expected proportion of false positives incurred when calling a feature significant.

\section{Cis Regulatory Element (CRE) Detection Using Known CRES}

In order to detect known CREs that may be over-represented in a group of genes (e.g. N-bicluster 9, N/H-biclusters), sequence analysis of the promoter regions of these genes was performed. We used Cis Regulatory Element (CRE) annotation from the AGRIS Database (Arabidopsis Gene Regulatory Information Server [68]) as well as our own literature search to identify biologically active CREs that have been validated by in vivo experimentation. CRE detection was performed using the DNA pattern search tool available from RSA Tools [47] upon 3,000 bp of parsed upstream promoter region (taken from the AGRIS database).

The test for over-representation of CREs was performed using Fisher's Exact Test. This test compared the proportion of promoters in which a particular CRE of interest appeared in one group with the proportion of these same CREs detected in another group. A p-value cutoff was computed using a 5\% FDR cut-off for significance.

\section{Authors' contributions}

GC, GK, DT and DN designed the study. DT and DN performed statistical analysis. GK and DN wrote the paper. All authors read and approved the final version of the manuscript.

\section{Additional material}

\section{Additional file 1}

Additional Tables and Legends. Contains all Additional Table and legend cited above including: 1) Summary Table of C/N Datasets Used to Generate N-biclusters; 2) BioMaps Analysis of N-biclusters; 3) N-bicluster 9 gene list; 4) Results of N/H Biclustering; 5) Significant H-biclusters Over-represented Functional Categories; 6) Hormone Microarray Datasets.

Click here for file

[http://www.biomedcentral.com/content/supplementary/17520509-3-59-S1.pdf]

\section{Additional file 2}

ANOVA [R] script and results. Contains the entire commented procedure of the ANOVA analysis, comparing $\mathrm{N} / \mathrm{H}$ controlled genes vs. $\mathrm{N}$ exclusive genes.

Click here for file

[http://www.biomedcentral.com/content/supplementary/1752-

0509-3-59-S2.pdf]

\section{Acknowledgements}

We thank Sandrine Ruffel, and Miriam Gifford for helpful discussion and critical reading of the manuscript. We thank Dennis Shasha for his help in determining the statistical significance of the connectivity of multinetworks. This work was funded by NIH NIGMS GRANT GM032877 to G.C., an NIH Pre-doctoral minority fellowship GM032877-SI to D.N., and an NSF Arabidopsis 2010 Genome Grant (IOB 05I 9985) to G.C.

\section{References}

I. Crawford NM, Glass ADM: Molecular and physiological aspects of nitrate uptake in plants. Trends in Plant Science 1998, 3(I0):389-395.

2. Gutierrez RA, Gifford ML, Poultney C, Wang R, Shasha DE, Coruzzi $G M$, Crawford NM: Insights into the genomic nitrate response using genetics and the Sungear Software System. J Exp Bot 2007, 58(9):2359-2367.

3. Krouk G, Tranchina D, Lejay L, Cruikshank AA, Shasha D, Coruzzi GM, Gutierrez RA: A Systems Approach Uncovers Restrictions for Signal Interactions Regulating Genome-wide Responses to Nutritional Cues in Arabidopsis. PLoS Comput Biol 2009, 5(3): el 000326.

4. Rubio V, Bustos R, Irigoyen ML, Cardona-Lopez X, Rojas-Triana M, Paz-Ares J: Plant hormones and nutrient signaling. Plant Mol Biol 2009, 69(4):36I-373.

5. Sakakibara $\mathrm{H}$, Takei K, Hirose $\mathrm{N}$ : Interactions between nitrogen and cytokinin in the regulation of metabolism and development. Trends Plant Sci 2006, I I (9):440-448.

6. Avery GS, Pottorf $\mathrm{L}$ : Auxin and nitrogen relationshinps in green plants. American Journal of Botany 1945, 32:666-669.

7. Guo FQ, Wang R, Crawford NM: The Arabidopsis dual-affinity nitrate transporter gene AtNRTI.I (CHLI) is regulated by auxin in both shoots and roots. J Exp Bot 2002, 53(370):835-844.

8. Signora $L$, De Smet I, Foyer CH, Zhang H: ABA plays a central role in mediating the regulatory effects of nitrate on root branching in Arabidopsis. Plant J 200I, 28(6):655-662.

9. Takei K, Ueda N, Aoki K, Kuromori T, Hirayama T, Shinozaki K, Yamaya T, Sakakibara H: AtIPT3 is a key determinant of nitratedependent cytokinin biosynthesis in Arabidopsis. Plant Cell Physiol 2004, 45(8): 1053-1062.

10. Miyawaki K, Matsumoto-Kitano M, Kakimoto T: Expression of cytokinin biosynthetic isopentenyltransferase genes in Arabidopsis: tissue specificity and regulation by auxin, cytokinin, and nitrate. Plant J 2004, 37(1): 128-138.

II. Sakakibara H: Nitrate-specific and cytokinin-mediated nitrogen signaling pathways in plants. J Plant Res 2003, i 16(3):253-257.

12. Takei K, Takahashi T, Sugiyama T, Yamaya T, Sakakibara H: Multiple routes communicating nitrogen availability from roots to shoots: a signal transduction pathway mediated by cytokinin. J Exp Bot 2002, 53(370):97।-977.

13. Takei K, Sakakibara H, Taniguchi M, Sugiyama T: Nitrogen-dependent accumulation of cytokinins in root and the translocation to leaf: implication of cytokinin species that induces gene expression of maize response regulator. Plant Cell Physiol 200 I, 42(I):85-93.

14. Rahayu YS, Walch-Liu P, Neumann G, Romheld V, von Wiren N, Bangerth F: Root-derived cytokinins as long-distance signals for $\mathrm{NO}_{3}$-induced stimulation of leaf growth. J Exp Bot 2005, 56(4 I4): I |43-II52. 
15. Drew MC: Comparison of the effects of a localized supply of phosphate, nitrate, ammonium and potassium on the growth of the seminal root system, and the shoot, in barley. New Phyt 1975, 75:479-490.

16. Walch-Liu P, Filleur S, Gan Y, Forde BG: Signaling mechanisms integrating root and shoot responses to changes in the nitrogen supply. Photosynthesis research 2005, 83(2):239-250

17. Walch-Liu P, Ivanov II, Filleur S, Gan Y, Remans T, Forde BG: Nitrogen regulation of root branching. Ann Bot (Lond) 2006, 97(5):875-88।.

18. Zhang H, Jennings A, Barlow PW, Forde BG: Dual pathways for regulation of root branching by nitrate. Proc Natl Acad Sci USA 1999, 96(II):6529-6534.

19. Dharmasiri S, Swarup R, Mockaitis K, Dharmasiri N, Singh SK, Kowalchyk M, Marchant A, Mills S, Sandberg G, Bennett MJ, et al.: AXR4 is required for localization of the auxin influx facilitator AUXI. Science 2006, 3 I2(5777): $1218-1220$.

20. Remans T, Nacry P, Pervent M, Filleur S, Diatloff E, Mounier E, Tillard P, Forde BG, Gojon A: The Arabidopsis NRTI.I transporter participates in the signaling pathway triggering root colonization of nitrate-rich patches. Proc Natl Acad Sci USA 2006 103:19206-19211.

21. Krouk G, Tillard P, Gojon A: Regulation of the high-affinity NO3- uptake system by NRTI.I-mediated NO3-demand signaling in Arabidopsis. Plant Physiol 2006, I 42(3): I 075- 1086.

22. Muños S, Cazettes C, Fizames C, Gaymard F, Tillard P, Lepetit M, Lejay L, Gojon A: Transcript profiling in the chI I-5 mutant of Arabidopsis reveals a role of the nitrate transporter NRTI.I in the regulation of another nitrate transporter, NRT2.I. Plant Cell 2004, I6(9):2433-2447.

23. Walch-Liu P, Forde BG: Nitrate signalling mediated by the NRTI.I nitrate transporter antagonises L-glutamateinduced changes in root architecture. Plant J 2008, 54(5):820-828.

24. Hartigan J: Clustering algorithms. New York, NY, USA: John Wiley \& Sons; 1975.

25. Tanay ASR, Shamir R: Discovering statistically significant Biclusters that are associated with replication origins. Curr Biology 1999, 9:R66I-R667.

26. Wang R, Okamoto $M$, Xing $X$, Crawford NM: Microarray analysis of the nitrate response in Arabidopsis roots and shoots reveals over I,000 rapidly responding genes and new linkages to glucose, trehalose-6-phosphate, iron, and sulfate metabolism. Plant Physiol 2003, I32(2):556-567.

27. Wang R, Tischner R, Gutierrez RA, Hoffman M, Xing X, Chen $M$, Coruzzi G, Crawford NM: Genomic analysis of the nitrate response using a nitrate reductase-null mutant of Arabidopsis. Plant Physiol 2004, I36(I):25I 2-2522.

28. Scheible W-R, Morcuende R, Czechowski T, Fritz C, Osuna D, Palacios-Rojas N, Schindelasch D, Thimm O, Udvardi MK, Stitt M: Genome-wide reprogramming of primary and secondary metabolism, protein synthesis, cellular growth processes, and the regulatory infrastructure of Arabidopsis in response to nitrogen. Plant Physiol 2004, I 36(I):2483-2499.

29. Palenchar PM, Kouranov A, Lejay LV, Coruzzi GM: Genome-wide patterns of carbon and nitrogen regulation of gene expression validate the combined carbon and nitrogen $(\mathrm{CN})$-signaling hypothesis in plants. Genome Biol 2004, 5(II):R9I.

30. Gutierrez RA, Lejay LV, Dean A, Chiaromonte F, Shasha DE, Coruzzi GM: Qualitative network models and genome-wide expression data define carbon/nitrogen-responsive molecular machines in Arabidopsis. Genome Biol 2007, 8(I):R7.

31. Sharan R: M-KAaSR: CLICK and EXPANDER: A System for Clustering and Visualizing Gene Expression Data. Bioinformatics 2003, I9(14): 1787-1799.

32. Tanay A, Sharan R, Kupiec M, Shamir R: Revealing modularity and organization in the yeast molecular network by integrated analysis of highly heterogeneous genomewide data. Proc Natl Acad Sci USA 2004, I 0 I(9):298I-2986.

33. Schoof $H$, Zaccaria $P$, Gundlach $H$, Lemcke $K$, Rudd $S$, Kolesov $G$, Arnold R, Mewes HW, Mayer KF: MIPS Arabidopsis thaliana Database (MAtDB): an integrated biological knowledge resource based on the first complete plant genome. Nucleic Acids Res 2002, 30(1):91-93.
34. Madar A, Bonneau R: Learning global models of transcriptional regulatory networks from data. Methods in molecular biology (Clifton, NJ) 2009, 541:181.

35. Gan RR, Yi EC, Chiu Y, Lee H, Kao YC, Wu TH, Aebersold R, Goodlett DR, Ng WV: Proteome analysis of Halobacterium sp. NRC-I facilitated by the biomodule analysis tool BMSorter. Mol Cell Proteomics 2006, 5(6):987-997.

36. Bonneau R: Learning biological networks: from modules to dynamics. Nat Chem Biol 2008, 4(I I):658-664.

37. Thum KE, Shin MJ, Gutierrez RA, Mukherjee I, Katari MS, Nero D, Shasha D, Coruzzi GM: An integrated genetic, genomic and systems approach defines gene networks regulated by the interaction of light and carbon signaling pathways in Arabidopsis. BMC systems biology 2008, 2:31

38. Cerezo M, Tillard P, Filleur S, Munos S, Daniel-Vedele F, Gojon A Major alterations of the regulation of root $\mathrm{NO}_{3}^{-}$uptake are associated with the mutation of Nrt2.I and Nrt2.2 genes in Arabidopsis. Plant Physiol 200I, I 27(I):262-27I.

39. Gutierrez RA, Stokes TL, Thum K, Xu X, Obertello M, Katari MS, Tanurdzic M, Dean A, Nero DC, McClung CR, et al.: Systems approach identifies an organic nitrogen-responsive gene network that is regulated by the master clock control gene CCAI. Proc Natl Acad Sci USA 2008, I05( I 2):4939-4944.

40. Ruffel S, Freixes S, Balzergue S, Tillard P, Jeudy C, Martin-Magniette ML, Merwe MJ van der, Kakar K, Gouzy J, Fernie AR, et al.: Systemic signaling of the plant nitrogen status triggers specific transcriptome responses depending on the nitrogen source in Medicago truncatula. Plant Physiol 2008, 146(4):2020-2035.

4I. Zhuo D, Okamoto M, Vidmar J], Glass AD: Regulation of a putative high-affinity nitrate transporter (Nrt2; IAt) in roots of Arabidopsis thaliana. Plant / 1999, 17(5):563-568.

42. Brenner WG, Romanov GA, Kollmer I, Burkle L, Schmulling T: Immediate-early and delayed cytokinin response genes of Arabidopsis thaliana identified by genome-wide expression profiling reveal novel cytokinin-sensitive processes and suggest cytokinin action through transcriptional cascades. Plant J 2005, 44(2):3|4-333.

43. Gan Y, Filleur S, Rahman A, Gotensparre S, Forde BG: Nutritional regulation of ANRI and other root-expressed MADS-box genes in Arabidopsis thaliana. Planta 2005, 222(4):730-742.

44. Craigon DJ, James N, Okyere J, Higgins J, Jotham J, May S: NASCArrays: a repository for microarray data generated by NASC's transcriptomics service. Nucleic Acids Res 2004:D575-577.

45. Team RDC: A language and environment for statistical computing. R Foundation for Statistical Computing, Vienna, Austria; 2007.

46. Crawley MJ: Statistics: an introduction using R. Volume I. Ist edition. New York: John Wiley \& Sons; 2005.

47. van Helden JAB, Collado-Vides J: A web site for the computational analysis of yeast regulatory sequences. Yeast 2000 , I6(2): 177-187.

48. Littlefield $\mathrm{O}$, Nelson $\mathrm{HC}$ : A new use for the 'wing' of the 'winged' helix-turn-helix motif in the HSF-DNA cocrystal. Nat Struct Biol 1999, 6(5):464-470.

49. Vandepoele K, Vlieghe K, Florquin K, Hennig L, Beemster GT, Gruissem W, Peer Y Van de, Inze D, De Veylder L: Genome-wide identification of potential plant E2F target genes. Plant Physiol 2005, 139(I):316-328.

50. Baliga NS, Pan M, Goo YA, Yi EC, Goodlett DR, Dimitrov K, Shannon $P$, Aebersold $\mathrm{R}, \mathrm{Ng}$ WV, Hood L: Coordinate regulation of energy transduction modules in Halobacterium sp. analyzed by a global systems approach. Proc Natl Acad Sci USA 2002, 99(23):14913-14918.

5I. Bonneau R, Facciotti MT, Reiss DJ, Schmid AK, Pan M, Kaur A, Thorsson V, Shannon P, Johnson MH, Bare JC, et al.: A predictive model for transcriptional control of physiology in a free living cell. Cell 2007, I 3 I (7): 1354-1365.

52. Franco-Zorrilla JM, Martin AC, Leyva A, Paz-Ares J: Interaction between phosphate-starvation, sugar, and cytokinin signaling in Arabidopsis and the roles of cytokinin receptors CRE I/ AHK4 and AHK3. Plant Physiol 2005, I 38(2):847-857.

53. Franco-Zorrilla JM, Martin AC, Solano R, Rubio V, Leyva A, Paz-Ares J: Mutations at CREI impair cytokinin-induced repression of phosphate starvation responses in Arabidopsis. Plant J 2002, 32(3):353-360. 
54. Moore B, Zhou L, Rolland F, Hall Q, Cheng WH, Liu YX, Hwang I, Jones T, Sheen J: Role of the Arabidopsis glucose sensor HXK I in nutrient, light, and hormonal signaling. Science 2003, 300(56I7):332-336

55. Maruyama-Nakashita A, Nakamura Y, Yamaya T, Takahashi H: A novel regulatory pathway of sulfate uptake in Arabidopsis roots: implication of CRE I/WOL/AHK4-mediated cytokinindependent regulation. Plant J 2004, 38(5):779-789.

56. Seguela $M$, Briat JF, Vert G, Curie C: Cytokinins negatively regulate the root iron uptake machinery in Arabidopsis through a growth-dependent pathway. Plant J 2008, 55(2):289-300.

57. Nover L, Bharti K, Doring P, Mishra SK, Ganguli A, Scharf KD: Arabidopsis and the heat stress transcription factor world: how many heat stress transcription factors do we need? Cell stress \& chaperones 200I, 6(3): I77-189.

58. Kotak S, Larkindale J, Lee U, von Koskull-Doring P, Vierling E, Scharf KD: Complexity of the heat stress response in plants. Curr Opin Plant Biol 2007, I0(3):310-316.

59. Poultney CS, Gutierrez RA, Katari MS, Gifford ML, Paley WB, Coruzzi GM, Shasha DE: Sungear: interactive visualization and functional analysis of genomic datasets. Bioinformatics 2007, 23(2):259-261.

60. Nemhauser JL, Hong F, Chory J: Different plant hormones regulate similar processes through largely nonoverlapping transcriptional responses. Cell 2006, I 26(3):467-475.

61. Inze D: Green light for the cell cycle. Embo J 2005 24(4):657-662.

62. Blais A, Dynlacht BD: E2F-associated chromatin modifiers and cell cycle control. Current opinion in cell biology 2007, 19(6):658-662.

63. Vlieghe K, Vuylsteke M, Florquin K, Rombauts S, Maes S, Ormenese S, Van Hummelen P, Peer Y Van de, Inze D, De Veylder L: Microarray analysis of E2Fa-DPa-overexpressing plants uncovers a cross-talking genetic network between DNA replication and nitrogen assimilation. J Cell Sci 2003, I l 6(20):4249-4259.

64. Cannons AC, Shiflett SD: Transcriptional regulation of the nitrate reductase gene in Chlorella vulgaris: identification of regulatory elements controlling expression. Current genetics 200I, 40(2): I28-I35.

65. del Pozo JC, Diaz-Trivino S, Cisneros N, Gutierrez C: The balance between cell division and endoreplication depends on E2FC DPB, transcription factors regulated by the ubiquitinSCFSKP2A pathway in Arabidopsis. Plant Cell 2006, I 8(9):2224-2235.

66. Shannon PMA, Ozier O, Baliga NS, Wang JT, Ramage D, Amin N, Schwikowski B, Ideker T: Cytoscape: A software environment for integrated models of biomolecular interaction networks. Genome Research 2003, 13:2498-2404.

67. Storey JD, Tibshirani R: Statistical significance for genomewide studies. Proc Natl Acad Sci USA 2003, 100 ( 16):9440-9445.

68. Davuluri RV, Sun H, Palaniswamy SK, Matthews N, Molina C, Kurtz M, Grotewold E: AGRIS: Arabidopsis gene regulatory information server, an information resource of Arabidopsis cis-regulatory elements and transcription factors. $B M C$ bioinformatics 2003, 4:25

Publish with Bio Med Central and every scientist can read your work free of charge

"BioMed Central will be the most significant development for disseminating the results of biomedical research in our lifetime. "

Sir Paul Nurse, Cancer Research UK

Your research papers will be:

- available free of charge to the entire biomedical community

- peer reviewed and published immediately upon acceptance

- cited in PubMed and archived on PubMed Central

- yours - you keep the copyright

Submit your manuscript here:

http://www.biomedcentral.com/info/publishing_adv.asp
BioMedcentral 